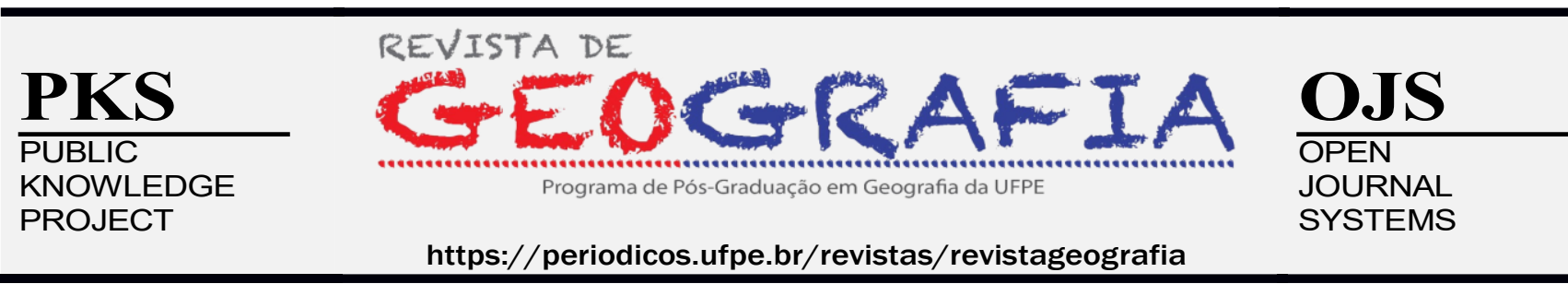

\title{
O PROFESSOR DE GEOGRAFIA DA EDUCAÇÃO BÁSICA NO ESTADO DO ACRE E OS DESAFIOS DE ENSINAR REMOTAMENTE
}

\author{
Iago Sales de Paula ${ }^{1}$, Lucilene Ferreira de Almeida ${ }^{2}$
}

\begin{abstract}
${ }^{1}$ Universidade Federal do Acre (UFAC). iago.ufac@gmail.com. Orcid: https://orcid.org/0000-0002-6380-0289
${ }^{2}$ Universidade Federal do Acre (UFAC). lulucageo@gmail.com. Orcid: https://orcid.org/0000-0002-2567-9983
\end{abstract}

Artigo recebido em 05/02/2021 e aceito em 04/10/2021

\begin{abstract}
RESUMO
Desde o dia 17 de março de 2020, com a confirmação dos três primeiros casos da Covid-19 no estado do Acre, as aulas presenciais das escolas da Educação Básica foram suspensas por tempo indeterminado e o ensino remoto passou a ser uma realidade para gestores, professores, alunos e seus responsáveis. Nesse contexto, objetivamos discutir os principais desafios no ensinar remotamente a disciplina de Geografia, a partir de aspectos relacionados aos meios tecnológicos, as novas atribuições docentes, a saúde mental dos professores, entre outros. A pesquisa foi desenvolvida através de pesquisa com professores de Geografia da Educação Básica, do estado do Acre, através de entrevistas e questionários, além de levantamento bibliográfico sobre ensino de Geografia, tecnologias e educação. Através da análise dos dados constatamos que o ensino remoto tem revelado uma série de dificuldades para os professores, principalmente pela pouca experiência com tecnologias e educação a distância. Além disso, revela a sobrecarga de trabalho, a insuficiência (ou má qualidade) de internet e equipamentos tecnológicos, além da saúde mental abalada ou fragilizado devido pandemia e o isolamento social. Portanto, em muitos aspectos foi possível constatar que o ensino remoto apenas trouxe à tona uma série de problemas que já vinham ocorrendo.
\end{abstract}

Palavras-chave: Ensino remoto. Professor de Geografia. Tecnologia e ensino.

\section{THE BASIC EDUCATION GEOGRAPHY TEACHER IN STATE OF ACRE AND THE CHALLENGES OF REMOTE TEACHING}

\begin{abstract}
Since March 17th, 2020, with the confirmation of the first three cases of Covid-19 in the state of Acre, faceto-face classes at Basic Education schools have been suspended indefinitely and remote teaching has become a reality for school managers, teachers, students and their guardians. In this context, we aim to discuss the main challenges in remotely teaching the subject of Geography, from aspects related to technological means, new teaching assignments, teachers' mental health, among others. The research was developed through research with Geography teachers of Basic Education, from the state of Acre, through interviews and questionnaires, in addition to a bibliographic survey on Geography teaching, technologies and education. Through data analysis, we established that remote education has revealed a series of difficulties for teachers,
\end{abstract}


mainly due to limited experience with technologies and distance education. Furthermore, it also reveals a work overload, insufficiency (or poor quality) of internet connection and technological equipment, in addition to the shaken or weakened mental health due to the pandemic and social isolation. Therefore, in many aspects it was possible to verify that remote education only brought to light a series of problems.

Keywords: Remote teaching; Geography teacher; Technology and education.

\section{INTRODUÇÃO}

Vivemos hoje tempos incertos, que revelam em todos os campos da sociedade o quanto os conhecimentos e descobertas humanas são limitadas a catástrofes sem dimensão prévia, como o coronavírus que tem atingido todo o planeta. Neste artigo apresentamos algumas discussões relacionadas à prática docente em tempos de pandemia, como resultados de pesquisas realizadas com professores de Geografia da Educação Básica do estado do Acre, que têm ensinado remotamente. O objetivo é analisar como tem sido a prática desses professores durante a pandemia e quais impactos essas mudanças trazem em seu cotidiano.

As questões que norteiam a pesquisa são: Como os/as professores/as têm trabalhado remotamente? Quais as principais dificuldades e desafios frente ao ensino remoto e ao uso de tecnologias para o ensino? Como ensinar Geografia remotamente? A pesquisa foi realizada com aplicação de questionários e entrevistas a professores/as de Geografia que atuam na Educação Básica, em escolas e institutos públicos e privados do estado do Acre; análise das questões e respostas dos questionários e entrevistas; pesquisa em sites governamentais; levantamento bibliográfico sobre ensino de Geografia, uso de tecnologias e ensino remoto.

O texto apresenta em sua primeira parte uma contextualização do ensino remoto em tempos de pandemia da Covid-19, no estado Acre. Em seguida são apresentadas as análises sobre a pesquisa realizada com os professores de Geografia do Acre. Os resultados direcionam para uma tendência identificada em outros estados brasileiros, em que as atividades a partir do ensino remoto, esbarram em diferentes contextos de diversidades sociais entre educadores e alunos, tornando esta experiência com o educar a distância não tão exitosa para os envolvidos. Para além das dificuldades apresentadas e a preocupação pelo momento em que todos vivenciamos, é inegável que professores têm se apropriado de ferramentas tecnológicas pouco presentes em seu cotidiano laboral e que procurado desenvolver seu trabalho a partir do ensino remoto. 


\section{SUSPENSÃO DAS AULAS PRESENCIAIS E ATIVIDADES REMOTAS NO ESTADO DO ACRE}

No dia 26 de fevereiro de 2020, o Ministério da Saúde registrava o primeiro caso de Covid19 no Brasil, mais especificamente no estado de São Paulo. Tratava-se de um senhor de 61 anos de idade que havia viajado para a Itália. No dia seguinte, são registrados 132 casos suspeitos de corona. Em 29 de fevereiro, o segundo caso da doença é confirmado. Dessa vez, um homem de 32 anos fora o acometido. A partir de então o número de casos, suspeitos e confirmados foi crescendo de maneira assustadora em todo o território nacional.

No dia 06 de março, chegava a 13 o número de casos confirmados, até que no dia 11 do mesmo mês, a Organização Mundial da Saúde (OMS) declarou estado de pandemia do coronavírus, confirmando que novos casos deveriam se multiplicar nos próximos dias, semanas e meses. No dia 17 de março é notificada a primeira morte ocasionada pela Covid-19 no Brasil. Concomitantemente são registrados os três primeiros casos do novo coronavírus no estado do Acre, menos de um mês depois do primeiro caso confirmado nacionalmente. Tais dados foram extraídos do Painel Coronavirus, o veículo oficial de comunicação sobre a situação epidemiológica da COVID-19 no Brasil (BRASIL, 2020a).

Essa breve linha temporal nos mostra o quanto esse vírus se propaga de maneira rápida. Em menos de um mês, conseguiu alcançar um país de proporções continentais como Brasil. Tão rápido quanto a propagação da doença pelo território foram as mudanças sociais, econômicas e educacionais ocasionados por ela. A situação decorrente desde então foi o fechamento de comércios e instituições públicas, incluindo nestas as escolas e universidades, colocando a população em isolamento para tentar conter o avanço do vírus. O campo educacional foi um dos mais afetados, como explica Arruda:

O novo coronavírus torna a escola um dos espaços mais temidos pelo risco da transmissão, pois a sua multiplicidade e heterogeneidade cria vínculos entre aqueles que são menos propensos aos sintomas graves da doença (jovens) a todos os demais que podem ser até mortalmente propensos. Crianças e jovens entram em contato diário com adultos de diferentes grupos familiares: professores, profissionais da educação, pais e mães, avós e avôs, parentes de maneira geral. Podemos afirmar que professores e estudantes se tornam os principais vetores de transmissão da Covid-19, diante disso as políticas mundiais de retorno às atividades coletivas têm deixado as escolas em último plano, conforme dados da ONU e UNESCO (2020). Em situações ainda mais graves, esses órgãos permitem um retorno com tantas determinações sanitárias que fazem com que a escola possivelmente não volte a ser reconhecida pelos seus atores. (ARRUDA, 2020, p. 259). 
Esse momento acabou definindo ou impondo outros meios e formas de ensino e aprendizagem tanto para professores quanto para os alunos da Educação Básica e Ensino Superior, em que as atividades remotas passaram a ser a alternativa mais defendida, principalmente por gestores.

No estado do Acre, as aulas da rede pública foram suspensas, assim como as atividades de outros setores, por meio do Decreto $\mathrm{n}^{\circ} 5.496$, de 20 de março. Passado o tempo de suspensão definido e com o aumento no número de casos e óbitos por conta da Covid-19, o Decreto $\mathrm{n}^{\circ}$ 6.056, de 01 de junho prorroga por mais um período as atividades e serviços definidos no decreto anterior.

$\mathrm{Na}$ área de educação, algumas medidas passaram a ser adotadas visando uma não paralização total das atividades escolares. Naquele momento muitas discussões, não apenas locais, mas a nível nacional, propunham a implantação de uma educação a distância como substituta para as aulas presenciais suspensas em todos os estados brasileiros, por conta da Covid-19. Nesse início, muito se confundiu o que se propunha para esse momento, com a modalidade de ensino EaD, Educação à Distância.

Ao longo do processo, com intervenções de diversos especialistas, fica entendido que as diversas atividades que passaram a ser desenvolvidas pelas escolas não tratavam da modalidade $\mathrm{EaD}$, mas sim de um modo específico e emergencial de ensino remoto, já que, ao contrário da Educação à Distância, estabelecia variadas formas de contato/relação entre alunos, professores e escolas, como entrega de atividades impressas, envio de atividades por e-mail, por WhatsApp, uso de aplicativos diversos, videoaulas em redes de TV, YouTube, entre outros.

Uma outra característica do ensino remoto é que, quando ocorrem as aulas online, elas têm data e horários pré-definidos, o que exige que os alunos tenham acesso à internet, equipamentos tecnológicos como smartphone, computador ou notebook com capacidade para armazenamento das atividades, ambientes com possibilidade de estudo e para aqueles de menores idades e/ou pouca familiaridade com recursos tecnológicos, o acompanhamento de um responsável durante as atividades remotas.

No Acre as atividades remotas vêm ocorrendo principalmente por meio de aulas transmitidas na TV e no rádio através do programa Escola em Casa, que contempla alunos tanto do ensino Fundamental II quanto do ensino Médio. A transmissão vem ocorrendo no canal Amazon Sat e nas rádios Aldeia e Difusora Acreana. Além disso, todos os conteúdos ficam salvos na plataforma educ.see.ac.gov.br, podendo ser acessados a qualquer momento pelos alunos. Concomitantemente os professores têm atuado principalmente por meio de grupos no WhatsApp, nos 
quais são enviadas diariamente atividades e novos conteúdos aos alunos. Em algumas escolas foram adotadas também apostilas contendo atividades de todas as disciplinas.

No dia 03 de agosto de 2020, durante o Fórum Estadual de Educação, fica decidido que as aulas presenciais no estado permanecerão suspensas e retornarão apenas no ano de 2021. Desse modo, mantem-se o ensino remoto pelos próximos meses do ano. Essa discussão e decisão foi acompanhada por diversas entidades sociais e por grande parte população acreana, que criou uma campanha nas redes sociais em prol da manutenção da suspensão das aulas presenciais nas escolas públicas do estado.

Consideramos que o retorno às aulas presenciais neste momento seria precipitado pois na maioria dos municípios acreanos os casos e óbitos pela Covid-19 ainda são altos, principalmente na capital do estado, Rio Branco, no entanto é preciso considerar em quais condições têm ocorrido as atividades remotas propostas e postas em prática pela Secretaria de Estado de Educação (SEE/AC), por meio das escolas e professores. É importante identificar e reconhecer as especificidades da população acreana e a partir daí, considerar as condições em que professores e principalmente os alunos têm participado dessas atividades.

Sobre as atividades remotas realizadas pelos professores, o uso das tecnologias é um dos maiores entraves, pois é sabido sobre o pouco uso de Tecnologias da Informação e Comunicação na prática docente, principalmente em escolas públicas. Apesar deste ser um tema recorrente no campo educacional, o acesso e uso das TICs é um problema que acompanha o professor desde a sua formação inicial. O que temos com o ensino remoto é a exigência de uma prática pouco existente na sala de aula.

Como tem ocorrido o trabalho dos professores de Geografia em tempos de pandemia da Covid-19? O uso de tecnologias para as aulas remotas representa alguma dificuldade para os professores? Esses são alguns dos questionamentos que fazemos e analisamos na segunda parte do texto, onde apresentamos como o ensino remoto tem ocorrido no nosso estado através de entrevistas e aplicação de questionários a professores de Geografia do Ensino Básico do Acre.

\section{ATIVIDADES REMOTAS E O TRABALHO DOS PROFESSORES DE GEOGRAFIA}

O ensino de maneira remota pode apresentar uma série de dificuldades para os professores, pois os mesmos não estão habituados a tal metodologia de ensino e muitas vezes não possuem os recursos necessários para promover um ensino de qualidade através das ferramentas online. Não 
estamos, com isso, afirmando que o ensino online seja inferior ou de menor qualidade que o ensino presencial, mas precisamos levar em consideração que, escolas e instituições que fazem uso de tal modalidade possuem todas as estruturas e ferramentas necessárias, e seu corpo docente já está habituado a tal demanda, tendo completo domínio e experiência sobre esse modelo de ensino. O que está sendo realizado durante a pandemia do Covid-19 é um ensino online de emergência, implantado em poucas semanas.

Planejar, preparar e desenvolver um curso universitário totalmente online costuma tomar de seis a nove meses antes da entrega. Os (as) professores (as) geralmente se sentem mais à vontade para ensinar online no segundo ou terceiro ciclo desses cursos. É impossível que, de um dia para o outro, todos os membros do corpo docente se tornem especialistas no ensino e aprendizagem online, na situação atual, em que os prazos de entrega variam de algumas semanas a um único dia. Embora existam recursos para os quais os (as) professores (as) possam recorrer para obter assistência, o tamanho da mudança exigida atualmente em muitos campi, pode sobrecarregar os sistemas que fornecem esses recursos e, provavelmente, ultrapassará suas capacidades. (HODGES et al, 2020, p.06).

Os professores das redes pública e privada de ensino, não tiveram a opção de escolher se queriam ou não aderir a esse modo de ensino remoto. Do total de professores entrevistados, pouco mais de $78 \%$ estão em atividade durante a pandemia da Covid-19. Desse total de professores que estão em atividade, 47,6\% estão trabalhando com carga horária reduzida, por conta das mudanças ocorridas com o ensino remoto (Ver Gráfico 01). Tais professores estão se dedicando a atividades diversas como: correções de exercícios/tarefas e apresentação de conteúdos em forma de revisão, o que, mesmo de forma remota, tem sido em menor quantidade. Ao mesmo tempo, $16,7 \%$ não tiveram nenhuma redução de sua carga horária e continuaram exercendo as mesmas atividades que vinham realizando nas escolas, mas agora de forma remota.

Houve ainda professores que tiveram uma ampliação na sua carga horária, correspondendo a um percentual de $9,5 \%$, pois além de manterem o ritmo que tinham em sala de aula, precisaram complementar principalmente com a gravação de videoaulas e planejamentos mais específicos para o momento. Dessa forma, a sobrecarga de trabalho foi aumentada, pois embora não seja mais necessário ir até a escola e ministrar as aulas de forma presencial, o tempo de organização e planejamento para uma aula remota e a quantidade de exercícios se ampliaram. 
Figura 1 - A atuação dos professores durante a pandemia da Covid-19.

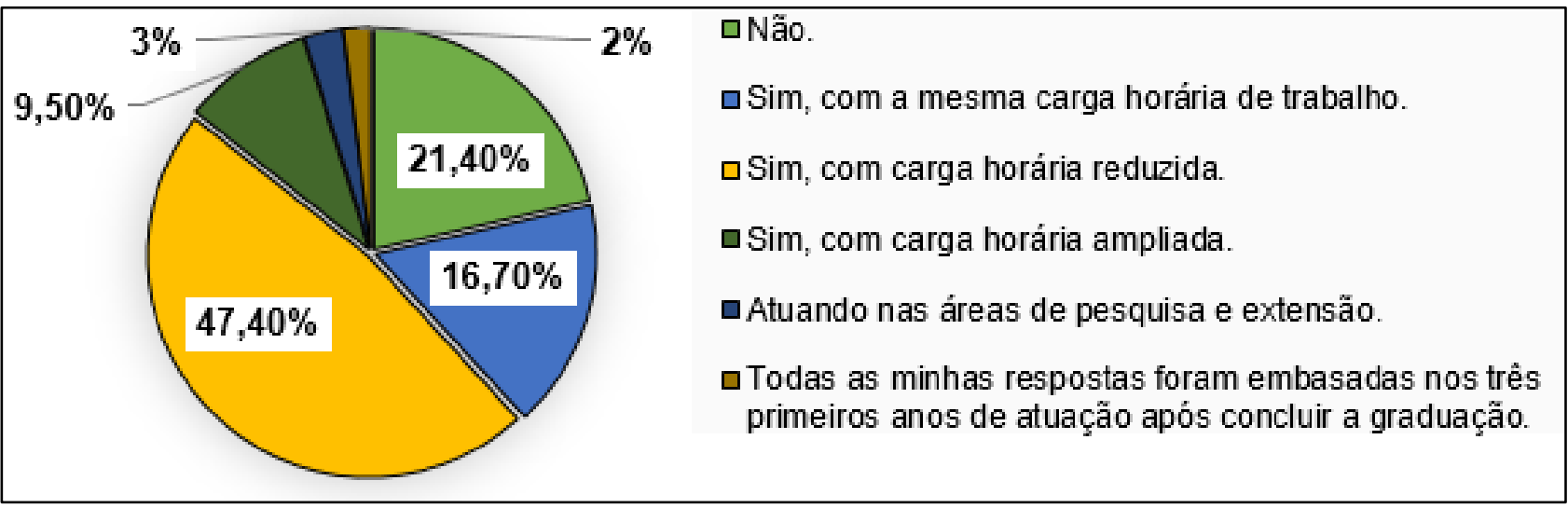

Fonte: Elaborado pelos autores (2020).

Entendemos nesse contexto que o trabalho do professor, entendido enquanto aquele que extrapola o tempo de ministração da aula (presencial ou online), não é totalmente considerado como carga horária de trabalho. Por mais que para o planejamento de aulas estejam atribuídas horas de trabalho, não são contabilizados o tempo utilizado para várias outras de atividades relacionadas ao processo de ensino. É nesse sentido que entendemos este enquanto um "trabalho invisível" e "não pago", e que, para Lopes e Mancebo (2004) compromete inclusive as relações familiares, que têm seus momentos ocupados pelo trabalho que não pode ser realizado dentro do tempo ou da carga horária paga.

\footnotetext{
Desse modo, o docente tem trabalhado exaustivamente em lives, produção de vídeos, aulas, conteúdos interativo, correção e auxílio aos alunos, superando a carga horária presencial. Muitos professores não têm mais uma rotina e nem tempo programada para as suas aulas, pois a docência está na casa, o Home Office, ou seja, trabalho remoto em casa e, com isto, amplia-se o atendimento ao aluno. É um desafio que outras profissões estão enfrentando também, a separação entre lazer e trabalho, já que o virtual protagoniza vários eventos. Ademais, os professores participam frequentemente de cursos de capacitação nas plataformas digitais, a fim de saber lidar com a educação nesta nova realidade de vida social. (MANFIO, 2020, p. 136).
}

A pesquisa mostrou também que um pouco mais da metade dos professores participantes receberam ou estão recebendo algum tipo de capacitação para atuar no ambiente remoto. A maior parte das capacitações foram oferecidas em formato de minicursos (carga horária de 2 horas cada), podendo ser acessados através do próprio site da SEE/AC (https://educ.see.ac.gov.br/pagina/capacitacao-ead). Tratam-se de cursos com instruções básicas para o uso de ferramentas digitais visando a educação a distância, sendo eles: o Podcast, o Webquest, os 
Grupos no Facebook, o Google Clasroom, o Google Docs, o Slarck, o Zoom Meetings, o Skype, o Google Livros e o Plataforma Educ.

Além dessas capacitações rápidas, foram oferecidos também uma série de outros cursos de formação com carga horária entre 10h e 180h, ofertados pela plataforma Ambiente Virtual de Aprendizagem do Ministério da Educação (AVAMEC). Todavia, esses cursos foram apenas indicados pela SEE/AC, e coube aos gestores a decisão de exigir ou não do seu corpo docente a realização destes. Dentre os principais cursos realizados pelos professores de Geografia, estão TIC's (Tecnologia da Informação e Comunicação), com carga horária de 60h e Formação para Articuladores do Programa de Inovação Educação Conectada, com carga horária de 180h, ambos oferecidos pelo AVAMEC.

Vale ressaltar que, conforme alguns professores, em algumas escolas não houve nenhuma obrigatoriedade por parte da gestão para que tais cursos fossem realizados pelo corpo docente, o que pode justificar os $42,9 \%$ de professores que não receberam qualquer capacitação, visto que o acesso aos cursos de curta duração ofertados pela SEE/AC eram de livre acesso a qualquer interessado.

Dos professores que realizaram algum treinamento ou capacitação, 58\% deles consideram que tais atividades não foram totalmente suficientes para o desenvolvimento de suas aulas remotas. Entre os relatos de alguns desses professores, os cursos oferecidos pela AVAMEC foram muito bem trabalhados, em especial o das TIC's, e que eles contribuíram de maneira muito positiva e satisfatória para o trabalho docente de forma remota. Em contrapartida, os cursos de curta duração oferecidos diretamente pela SEE/AC não tiveram contribuição significativa para o uso e manuseio das ferramentas digitais.

Temos ainda, entre os professores que realizaram algum curso e/ou treinamento, $26 \%$ que consideram que tais cursos não tiveram nenhuma contribuição para seu desempenho docente durante a pandemia. Através de conversas com alguns desses professores, foi possível identificar entre principais reclamações o despreparo por parte de quem ministrou esses cursos, o excesso de carga teórica e ao mesmo tempo a ausência de atividades mais práticas e principalmente a maneira superficial como as ferramentas de ensino a distância foram abordadas. Outra reclamação muito contundente por parte desses educadores foi a ausência de cursos voltados a ferramentas que auxiliassem na edição de vídeos, pois essa tem sido uma atividade constante durante as aulas remotas.

As questões apresentadas sobre formação e/ou capacitação para as atividades remotas, evidenciam uma questão mais complexa que é a pouca presença do uso se tecnologias nas aulas de Geografia em nossas escolas. Autores como Santos (2003), Castells (1999), Giddens (2000) discutem 
a velocidade em que as informações e os acontecimentos ocorrem para as sociedades modernas ou pós-modernas e, o avanço das tecnologias configura-se com o principal responsável por essa fluidez e conectividade entre as coisas e as pessoas.

A aclamação pelo uso de tecnologias no processo educativo não é de hoje, para Pretto (2011) esse uso relaciona-se com as linguagens resultantes da interação que os jovens têm com as tecnologias em seu cotidiano. Isso leva a modificações nas formas de escrever, na intensificação do uso de símbolos, ícones e imagens, tornando necessário que isso seja também acompanhado pelos espaços mais formais de educação e pelos educadores. Consenso é que há ainda um grande distanciamento entre ensino e o uso de tecnologias digitais.

Muitos são os motivos que justificam as dificuldades apontadas pelos professores para a realização de aulas remotas durante a pandemia, conforme mostra o Quadro 01. Numa lista de motivos e espaço para acréscimo de outros se necessário fosse para o participante da pesquisa, apresentamos aqui os seis mais mencionados por ordem de maior a menor referência e analisaremos cada um deles.

\section{Quadro 01 - Principais dificuldades no ensino remoto}

\begin{tabular}{|l|l|}
\hline $1^{\mathrm{o}}$ & Pouca ou nenhuma experiência com ensino remoto. \\
\hline $2^{\mathrm{o}}$ & $\begin{array}{l}\text { Conciliar diferentes atividades remotas com as tarefas de casa (cuidados } \\
\text { com a família, estudo dos filhos e outros). }\end{array}$ \\
\hline $3^{\mathrm{o}}$ & Internet e equipamentos tecnológicos insuficientes. \\
\hline $4^{\mathrm{o}}$ & Emocional abalado por conta da pandemia. \\
\hline $5^{\mathrm{o}}$ & Ficar doente durante a pandemia (por Covid-19 ou outras doenças). \\
\hline
\end{tabular}

Fonte: os autores (2020).

\section{$1^{\circ}$ Pouca ou nenhuma experiência com ensino remoto}

A dificuldade mais mencionada pelos professores de Geografia está relacionada a pouca ou nenhuma experiência com atividades realizadas a distância. Inclusive, em pergunta sobre a experiência com ensino a distância. De acordo com Hodges et al (2020) o fator experiência é muito importante para se trabalhar com o ensino remoto, pois os professores apenas se sentirão à vontade para lecionar sobre essa perspectiva a partir de alguns ciclos de experiências, assim como ocorre com as aulas presenciais, por exemplo.

Dos professores participantes da pesquisa, apenas 5\% tinham alguma experiência com educação a distância, justificando assim ser este o motivo mais mencionado entre as dificuldades em 
ensinar remotamente nesse momento. Considerando que $95 \%$ dos professores estão vivenciando agora o trabalho remoto, é importante manter a cautela em todo esse processo, visto que, a não ser que a corrida seja por números, tanto alunos como professores encontram-se num caminho de aprendizado.

Perguntados sobre experiências com TICs em suas aulas de Geografia antes da pandemia, as respostas refletem o ainda distanciamento que o campo educacional tem com os meios tecnológicos enquanto recursos educativos. Entre os entrevistados apenas 16,7\% afirmam ter muita experiência com TICs em suas aulas antes da pandemia. A maioria, 71,4\% confirma ter pouca experiência e 11,9\% nunca experimentaram em suas aulas qualquer tecnologia (Gráfico 02).

Figura 02 - Professores de Geografia: experiência com TICs antes da pandemia da Covid-19

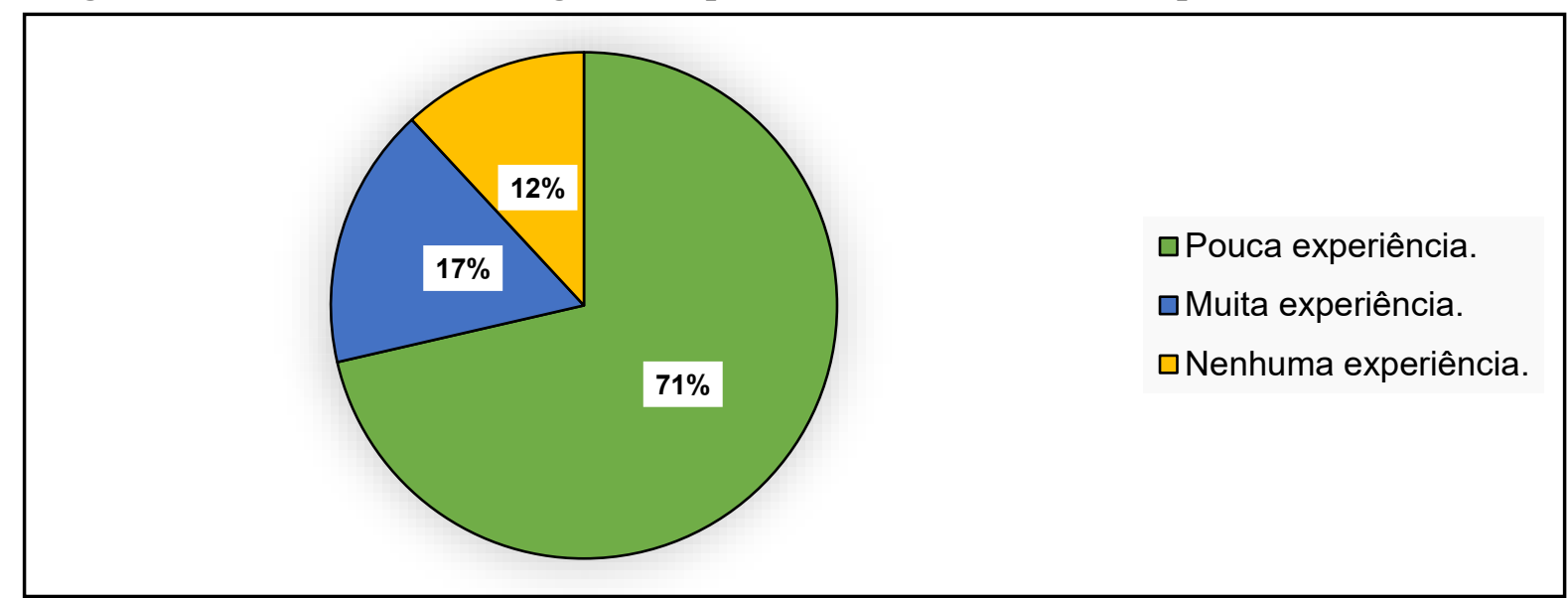

Fonte: Elaborado pelos autores (2020).

O número que mais chama atenção é dos que nunca tiveram qualquer experiência com tecnologias em suas aulas de Geografia. Considerando que há entre os participantes, professores que trabalham em escolas rurais, esta porcentagem pode concentrar-se entre estes, no entanto, podemos identificar também a presença de educadores de escolas urbanas.

Entre os que afirmam ter tido algumas (muito ou pouca) experiência com TICs em suas aulas antes da pandemia (71,4\%), em uma lista de possibilidades, a mais mencionada, por $88 \%$ dos participantes, foi o projetor multimídia e notebook (ou computador), 9,5\% mencionou o uso de lousa digital e 2,4\% de celular e QR Code. Os resultados apontam para o distanciamento que ainda temos entre educação e tecnologias. Isso se dá principalmente nas escolas públicas, onde os poucos investimentos são revestidos para outras necessidades, criando até por parte de alguns professores uma certa recusa em ter o uso das tecnologias como uma prática do seu cotidiano escolar. Nesse 
sentido, Pretto (2011) chama a atenção para a necessidade de intensificar o uso das TICs e inseri-la enquanto parte da cultura da escola, dos educadores e dos alunos e, não apenas como aparato tecnológico.

\section{$2^{\circ}$ Conciliar diferentes atividades remotas com as tarefas de casa}

Em segundo lugar temos como resposta dos professores que a dificuldade tem se dado por conta da conciliação entre as variadas tarefas a serem realizadas, considerando que, com o isolamento social, o local de moradia tornou-se também o local de trabalho e, para aqueles que têm filhos, tornouse também seu espaço de estudo. Nesse sentido, o acúmulo de atribuições se concentra num mesmo local.

\footnotetext{
Outro aspecto importante é que, em virtude do distanciamento social, tanto o trabalho dos professores quanto dos estudantes deve ocorrer na própria residência, no contexto da vida familiar. Com isso, o trabalho remoto ocorre no mesmo espaço que as atividades domésticas, dividindo o tempo de trabalho com o de cuidado de outros membros da família. Por isso, tiveram que se adaptar a uma situação sem precedentes, com consequências sociais e psicológicas de elevada complexidade. (GOMES et al, 2020, p. 309-310).
}

Infelizmente, precisamos considerar aqui que esta dificuldade apresentada ainda é maior entre as professoras do sexo feminino, que representam nesta pesquisa $61 \%$. Somam-se às atividades escolares (planejamento, produção de material didático, correção de atividades, gravar videoaulas, preparar material para enviar para os alunos, entre outros) as tarefas domésticas e o cuidado com os filhos, que inclusive, precisam de acompanhamento em suas atividades escolares. Desencadeia-se assim uma rotina em que aquele trabalho escolar, antes "invisível”, passa a juntar-se com o trabalho doméstico.

\section{$3^{\circ}$ Internet e equipamentos tecnológicos insuficientes}

Em terceiro temos como motivo que dificulta as atividades remotas, a questão do acesso à internet e a posse de equipamentos tecnológicos com capacidade para baixar aplicativos, armazenar arquivos, entre outros. No que diz respeito à internet, a ausência ou a má qualidade das redes disponíveis em suas casas em muito influencia o trabalho realizado. Tem-se também que esta é uma das principais dificuldades por parte dos alunos e isso em algumas localidades das cidades, impossibilita o trabalho remoto.

Entre os professores de Geografia que estão em atividade no período da pandemia, 90,5\% utilizam internet própria, enquanto os demais (menos de 10\%) utilizam do local de trabalho ou da 
casa de parentes. Dos que utilizam internet própria, $80 \%$ possuem conexão por Banda Larga e $20 \%$ por Dados Móveis. A constância das atividades remotas (reuniões, encontros pedagógicos, videoaulas, envio e recebimento de material e atividades, contato com alunos) exigiu que alguns ampliassem a velocidade da conexão e/ou adquirissem equipamentos com mais funcionalidade e armazenamento. No entanto, é importante considerar que, em todo estado do Acre, apesar da atuação de várias empresas, não há cobertura de boa qualidade em muitas localidades, principalmente nas cidades mais afastadas da capita, Rio Branco.

\begin{abstract}
Diante deste cenário escolar, inúmeros países discutiram internamente possibilidades de atendimento escolar em situações de excepcionalidade. É importante salientar que o contexto contemporâneo apresenta opções e possibilidades bem diferentes de emergências pandêmicas do passado. Uma delas diz respeito à disseminação de tecnologias digitais de informação e comunicação - sobretudo a Internet. (ARRUDA, 2020, p. 259).
\end{abstract}

Entre os principais relatos dos professores estão: a queda constante de sinal, o que pode ser explicado pelo grande número de pessoas que estão utilizando o serviço ao mesmo tempo, e a constante manutenção que as prestadoras desse serviço vêm realizando nos últimos meses. Essa situação é um agravamento sério e precisa ser levado em conta quando se pretende trabalhar com ferramentas que necessitem de acesso à rede de internet na área educacional.

\title{
$4^{\circ}$ Emocional abalado por conta da pandemia
}

O momento atual, vivenciado em todo o mundo, causou inúmeros desequilíbrios e entre estes o fator emocional tem sido bastante considerado. Para os professores, o emocional abalado por conta da pandemia foi o quarto motivo mais mencionado. Afirmam que tal situação tem sido negativamente determinante para justificar as dificuldades em suas atuações no campo do ensino e demais demandas cotidianas.

Um outro dado interessante e que merece ser ressaltado é que o psicológico dos professores (e da população, de uma maneira geral) está abalado. Conforme ficou claro no gráfico 5 , mais de 90\% dos professores estão, de alguma forma, preocupados com seu estado de saúde nesse contexto de pandemia. Atrelado a isso temos ainda uma série de preocupações relacionadas a casos próximos aos seus convívios, sejam parentes ou amigos próximos. Os próprios veículos de informação disseminam o tempo todo informações detalhadas sobre o coronavírus e seu avanço em nosso estado. Tudo isso gera uma instabilidade emocional e um grau de estresse muito grande sobre a população de uma forma geral. 
De acordo com Jair de Jesus Mari, médico psiquiatra, professor titular e chefe do Departamento de Psiquiatria da Escola Paulista de Medicina da Universidade Federal de São Paulo (2020), o isolamento social acaba impondo um novo ritmo de vida que muitas vezes leva a transtornos de saúde das pessoas. As principais consequências de todo esse ambiente de incertezas e dúvidas, são o medo de ser contaminado por um vírus invisível, a redução e o distanciamento de contatos físicos, o estresse agudo ocasionado por essa circunstância súbita e inesperada, além desequilíbrios hormonais, inflamatórios e neuroquímicos que acabam desencadeando um transtorno mental mais grave.

Ainda de acordo Mari (2020) o ajustamento a essa nova rotina acaba gerando situações de desamparo, tédio e raiva, acompanhados por ansiedade, irritabilidade e desconforto. Acrescenta-se a isso possíveis perdas econômicas e afetivas decorrentes dessa pandemia. Tudo isso gera danos psicológicos muito graves, que acabam se refletindo no trabalho docente.

Através dos questionários aplicados aos professores, constatamos que $90,5 \%$ deles não estão recebendo nenhum tipo de suporte emocional ou psicológico para auxiliar em suas atividades docentes. Isso revela uma situação preocupante, visto que, infelizmente, a profissão docente em nosso país já é, por si só, muito estressante. Os professores, portanto, não estão recebendo nenhum tipo de suporte para ministrarem suas aulas, o que resultará em uma diminuição da qualidade no processo de ensino-aprendizagem. Pudemos constatar que $70 \%$ dos professores que estão atuando durante esse período de pandemia gostariam de receber algum tipo de apoio psicológico, pois se encontram em algum dos casos elencados anteriormente de desgaste mental.

\section{$5^{\circ}$ Ficar doente durante a pandemia (por Covid-19 ou outras doenças)}

Entre os motivos que geram preocupação e por conseguinte acrescentam dificuldades para as atividades laborais durante a pandemia, na quinta colocação estão questões relacionadas à saúde dos professores ou de seus familiares. São principalmente casos relacionadas a familiares ou amigos que contraíram a Covid-19, falecimento de pessoas próximas ou mesmo o receio de contrair a doença e até mesmo o isolamento social, que os afastam de parentes e amigos.

Em relação às questões de saúde, muitos professores se mostraram preocupados com o momento atual, relatando que estão temerosos em contrair a Covid-19, mesmo que as atividades de trabalho não estejam ocorrendo de modo presencial (Gráfico 03). Dentre os participantes da pesquisa, apenas 4\% afirmam não ter qualquer preocupação com sua saúde neste momento, já 43\% estão um pouco preocupados. Entre esses dois grupos (nenhuma ou pouca preocupação com a saúde), apenas 
15\% fazem parte de algum dos grupos de riscos para a Covid-19, definidos pelo Ministério da Saúde, o que pode ser parte da justificativa para a pouca ou nenhuma preocupação com a saúde. Para além disso, não ter convivido diretamente com pessoas que foram infectadas ou mesmo se considerar assídua nos cuidados e prevenção em relação ao vírus, tranquiliza a maioria quanto a situação atual de contágios.

A preocupação com a saúde, que envolve não apenas o contágio pela Covid-19, mas com outras comorbidades, foi considerada muito ou total por $50 \%$ dos professores e, mesmo com $86 \%$ não fazendo parte do grupo de risco, se mostraram com uma preocupação maior com a situação atual. É possível inferir que esses professores acabaram convivendo diretamente com pessoas infectadas e testemunharam as consequências do coronavírus no organismo humano.

Ainda $2 \%$ dos participantes consideram que para este período, às questões de saúde que causam preocupação somam-se os níveis de estresse muito elevados devido ao aumento da jornada de trabalho com as atividades remotas

Figura 3 - Preocupação dos professores de Geografia em relação à própria saúde durante a pandemia.

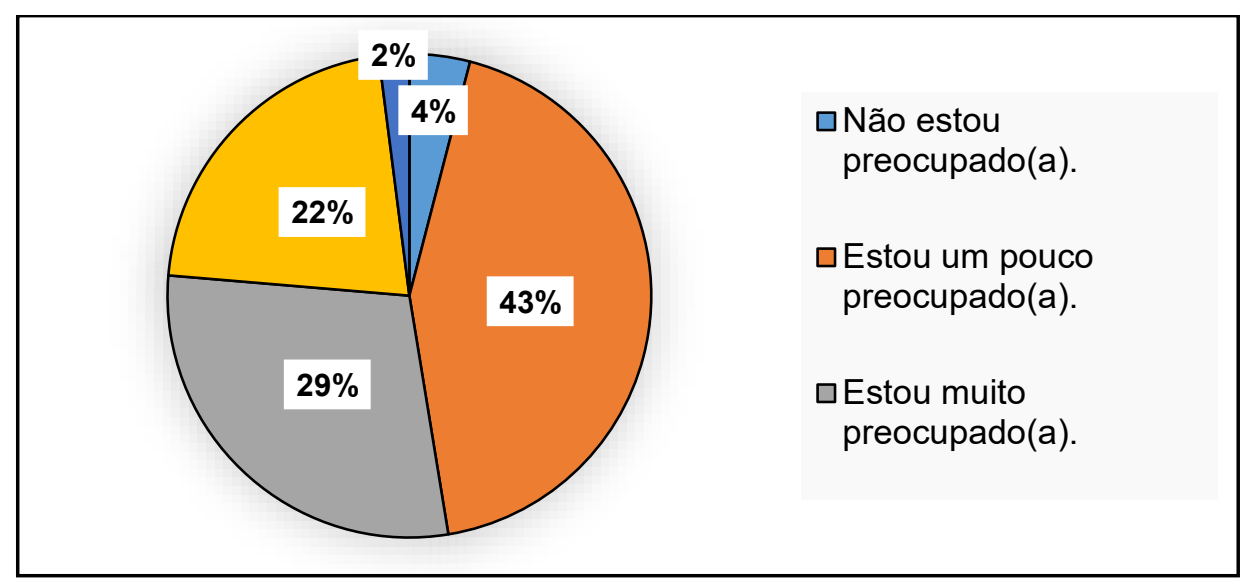

Fonte: Elaborado pelos autores (2020).

De acordo com o site do Ministério da Saúde, “[...] pessoas idosas e pessoas com condições médicas pré-existentes (como pressão alta, doenças cardíacas, doenças pulmonares, câncer ou diabete) estão mais suscetíveis a desenvolver casos mais severos de COVID-19.” (BRASIL, 2020). Mediante isso, $14,3 \%$ dos professores entrevistados apresentam alguma das características elencadas pelo Ministério da Saúde, se classificando, portanto, como grupo de risco (Gráfico 04).

Dentro desse grupo de professores, 44\% afirmaram que sua condição não foi levada em consideração no exercício da atividade docente, e que continuam exercendo suas atividades docentes 
normalmente de forma remota. Outros 33\% dos professores que fazem parte do grupo de risco afirmaram que, mediante atestado médico, conseguiram ser totalmente liberados de suas atividades docentes; e 22,2\% disseram que conseguiram uma liberação parcial de suas atividades. Provavelmente eles continuarão exercendo suas atividades de forma remota, mas com uma possível diminuição de carga horária.

\section{Figura 4 - Forma como o estado de saúde dos professores foi considerado durante o exercício de suas} atividades docentes.

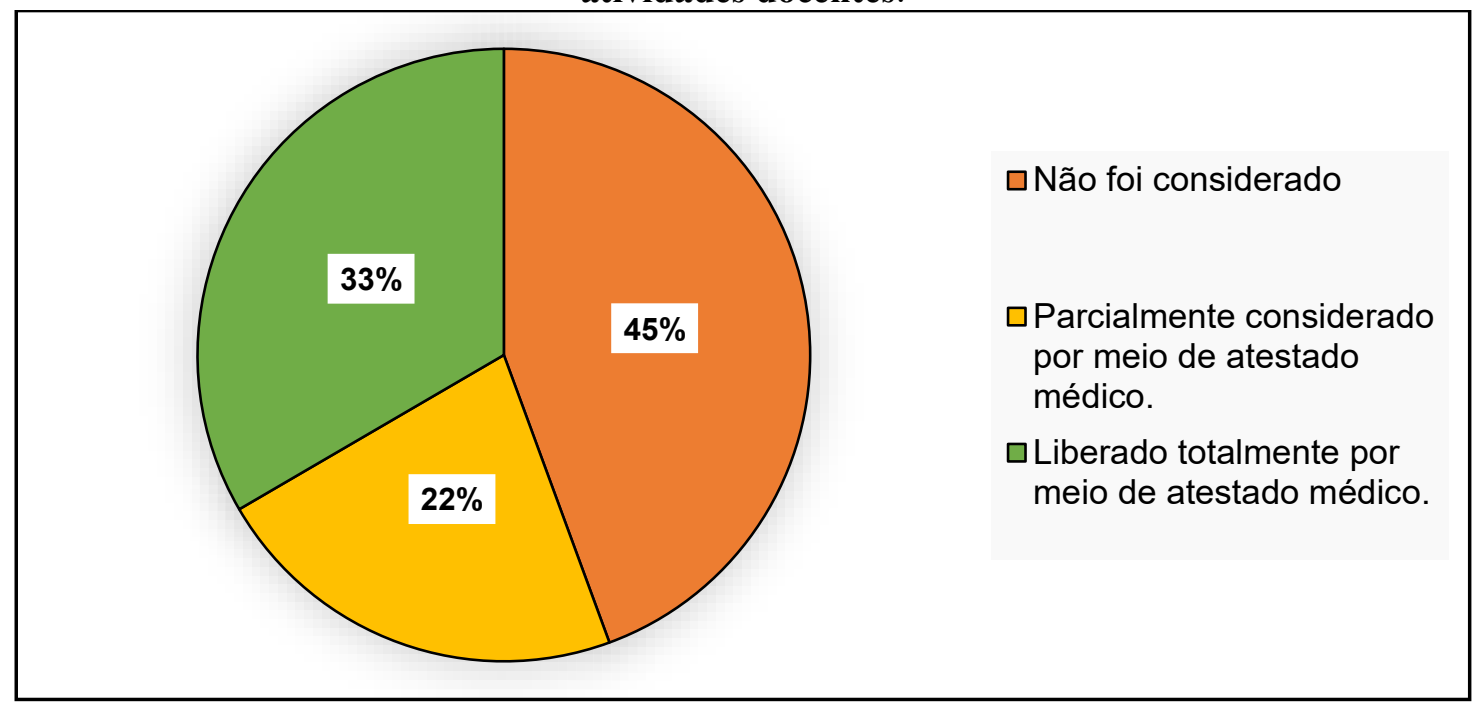

Fonte: Elaborado pelos autores (2020).

Os velhos e novos problemas vivenciados por professores e alunos evidenciam a realidade da educação brasileira. A participação dos alunos nas atividades remotas, incluindo as videoaulas e exercícios e materiais das disciplinas enviados por meios como WhatsApp, e-mails ou entregues impressos, têm sido muito aquém do esperado pelos professores e equipes gestoras. Segundos os professores de Geografia, menos de 50\% dos alunos têm participado das atividades.

Aqui, além da questão de acesso tecnológico, que exclui boa parte dos alunos sem condições de contratar um pacote de serviço de internet e/ou adquirir equipamentos que possibilitem acompanhar as atividades remotas, temos também, principalmente para os alunos de menores idades, a pouca participação da família no acompanhamento das atividades escolares. Para Singly (2007), o acompanhamento familiar é um investimento que os responsáveis pelo aluno fazem. É uma necessidade, pois através deste, identifica-se o que precisa ser melhor trabalhado, tanto por parte da escola como da família.

Sabido é que os motivos para que muitos alunos sejam pouco assistidos quanto as atividades escolares por suas famílias, estão entre os desafios da relação escola e comunidade escolar e não são 
específicos dos tempos de pandemia e as atividades remotas. Porém, é necessário considerar as mudanças causadas pelo isolamento social, em que as rotinas de trabalho ou mesmo a perda deste, somada a permanência dos alunos em casa, exigiu uma maior participação da família. Para aqueles que pais e responsáveis trabalham dois ou mais turnos e são os únicos que possuem ou sabem lidar com os equipamentos tecnológicos? E quando estes fazem parte dos excluídos tecnológicos?

Dos professores participantes da pesquisa, nenhum afirmou ter participação total dos alunos nas atividades remotas, nem mesmo aqueles que trabalham em escolas particulares. Nestas, a participação dos alunos se aproxima dos 90\% nas aulas remotas de Geografia nos anos finais do Ensino Fundamental e Ensino Médio. Isso leva-nos a entender que esse momento vem evidenciar tensões já existentes no campo educacional e na sociedade em geral.

A urgência para que já nas primeiras semanas os professores, agora assumido tarefas a partir de suas casas, realizassem a transposição de seus planejamentos para plataformas virtuais e recursos pela internet conduz à reprodução pura e simples da exposição oral presencial para a repetição à distância das explicações e exercícios. É um arremedo de proposta pedagógica. (FILHO, 2020, p. 6).

Ensinar remotamente tem sido um desafio para todos os professores, porém, há dificuldades mais específicas em ensinar remotamente a disciplina de Geografia? Esta pergunta foi feita aos participantes da pesquisa. Para a maioria dos professores, o ensino de Geografia através de atividades remotas apresenta dificuldades diversas, apenas $9 \%$ não identifica qualquer dificuldade para ensinar a disciplina remotamente. Entre as dificuldades mencionadas por 91\% dos entrevistados, algumas delas são comuns para qualquer disciplina ou atividade executada neste momento de pandemia, como o acesso à internet e a equipamentos tecnológicos.

Nos resultados destacaram-se aquelas respostas mais específicas para a disciplina de Geografia, melhor apresentadas a partir de algumas respostas dos professores. Para a Professora $A$ as dificuldades são "Demais, visto que nossa disciplina é muito visual, com mapas, tabelas e gráficos, fica difícil abordar alguns temas virtualmente". Nessa mesma direção o Professor $B$ esclarece que "Sim, [a dificuldade está] na explicação e manuseio dos mapas, cálculos, diferenciação de áreas, comparações, são mais complicados", acrescenta ainda que "Outra coisa é o contato social, o acompanhamento que fazemos dia a dia com os alunos, a fim de detectar suas dúvidas". Aqui temos além das especificidades da disciplina, a dificuldade pela falta do contato pessoal com o aluno, que é caracteriza qualquer ensino a distância. 
A abstração de algumas temáticas geográficas também foi citada como uma dificuldade no ensino remoto. Além destas, a dificuldade para baixar imagens e vídeos, a falta de recursos adequados e/ou suficiente, a imaturidade de parte dos alunos para lidar com esse modo de aprender, à distância, se destacam entre as respostas. No entanto, a maioria das respostas repousam no problema de acesso a internet e equipamentos tecnológicos.

Os conteúdos de Geografia considerados com maior nível de dificuldade para serem ensinados remotamente pelos professores de Geografia foram: conteúdos relacionados a cartografia, como fusos horários, coordenadas geográficas e escalas, foram mencionados por 58\% dos professores; conteúdos mais relacionados a Geografia Física, como estrutura da terra, movimento das placas tectônicas, intemperismo, erosão comportamento atmosférico e clima, foram mencionado por 27\% dos participantes da pesquisa; 6\%, mencionaram temas relacionados a Geografia Política e temas de Geografia Humana e, os demais, 9\%, afirmaram não identificar conteúdos que apresentem mais dificuldades para serem ensinados remotamente.

A rotina de atividades dos professores foi modificada por conta da variedade de novas tarefas a serem desenvolvidas para dar conta do ensino remoto. Nesse momento, para a maioria dos professores de Geografia as atividades laborais mais frequentes são: $1^{\circ}$ ) participação em grupos (como de WhatsApp); $2^{\circ}$ ) selecionar conteúdos e atividades de Geografia para as aulas remotas; $3^{\circ}$ ) correção de atividades/tarefas/exercícios; $4^{\circ}$ ) Construção/produção de material didático; e $5^{\circ}$ ) gravação de videoaulas. Além destas, em menor proporção foram mencionadas: editar vídeos, participar da entrega de atividades impressas para os alunos e gravação de aulas para rádio, gravação de áudios explicativos sobre os conteúdos.

Essa nova rotina é diversificada entre os professores, principalmente pela característica do ensino remoto praticado no estado Acre, onde há uma diversidade de atribuições para os professores, levando em conta principalmente os anos escolares que ensinam e a localização da escola e da moradia dos alunos. Isso define como ocorrem as atividades remotas, se por videoaulas: para anos escolares que compreendem a linguagem da TV e têm acesso a rede televisiva que transmite as aulas; por audioaulas: para alunos que residem em localidades onde só há acesso a conexão via rádio, muito comum nas áreas rurais do estado; envio de atividades e slides de aulas por grupos de WhatsApp, emails ou aplicativos como o Google Classrrom: voltado a todos os alunos que residem em localidades urbanas.

A maioria dos professores (70\%) reconhecem que neste momento de pandemia, as atividades escolares precisam estar mais voltadas para ensinar remotamente a partir das diferentes formas 
praticadas (videoaulas, entrega de atividades por e-mail, WhatsApp ou impressas, entre outros), conteúdos novos e revisão de conteúdos já trabalhados, mas paralelo a isso é necessário dar outras assistências para os alunos, como atendimento psicológico e reforço alimentar para os mais carentes. Entre os 30\% de professores participantes da pesquisa, a maioria considera que as atividades precisam apenas ser de ensinar remotamente os conteúdos planejados para o ano letivo, para que os alunos tenham qualquer atraso, enquanto uma minoria pontua que trabalhar apenas atividades voltadas para o bem estar da saúde mental dos alunos, sem cobrança de conteúdo, seria o mais correto neste momento.

Os resultados nessa questão evidenciam que os professores têm uma preocupação com o processo de aprendizagem dos alunos, também que reconhecem que para além do ensinar, é necessário intervir em questões que agravam a saúde mental e o bem-estar dos alunos, papel que a escola já desempenha, acompanhando uma necessidade social e econômica dos alunos.

\section{CONSIDERAÇÕES FINAIS}

Há de se considerar que vivemos um momento atípico para todas as pessoas. Aqui apresentamos como as atividades escolares, a partir das ações dos professores de Geografia da Educação Básica, no estado do Acre, têm sido desenvolvidas. As especificidades locais precisam ser consideradas, tanto para que professores e alunos consigam se inserir o máximo possível nesse processo que é novo para todos.

O ensinar Geografia remotamente está envolto de vários desafios e fica evidente nesta pesquisa o quão difícil tem sido perceber o quanto estamos (ou estávamos?) distantes do mundo digital. Foi necessária uma corrida pelos aparatos tecnológicos, que ainda não se tornaram acessíveis a todos os professores, porém, mais que a deles, é difícil a situação de acesso ao mundo digital dos seus alunos.

O trabalho do professor de Geografia da Educação Básica no Acre, revela problemas já existentes no contexto da educação, como a pouca presença da tecnologia parte como cultura da escola e seus sujeitos, mas revela também, nestes tempos de pandemia que há necessidade de mudanças na formação desse professore e no trabalho didático e pedagógico que este desenvolve em sala de aula. Para além dos problemas, é importante considerar o esforço e compromisso desses educadores com seu trabalho que para a maioria deles, se multiplicou com o isolamento social e a consequente paralização do ensino presencial. 


\section{REFERÊNCIAS}

ACRE. Secretaria de Estado de Educação, Cultura e Esportes. Capacitação Para Professores em Ferramentas Digitais Para Uso em EAD. Disponível em: https://educ.see.ac.gov.br/pagina/capacitacao-ead. Acesso em: 14 ago. 2020.

ARRUDA, Eucidio Pimenta. Educação Remota Emergencial: elementos para políticas públicas na educação brasileira em tempos de Covid-19. Em Rede: revista de educação à distância, v. 7, n. 1, 2020. Disponível em: https://www.aunirede.org.br/revista/index.php/emrede/article/view/621. Acesso em: 15 ago. 2020.

BRASIL. Painel Coronavírus. Disponível em: https://covid.saude.gov.br/. Acesso em: 14 ago. 2020.

BRASIL. Ministério da Saúde. Quem está mais vulnerável à COVID-19?. Disponível em: https://coronavirus.saude.gov.br/index.php/perguntas-e-respostas. Acesso em: 15 ago. 2020.

CASTELLS, Manuel. A sociedade em rede. São Paulo: Paz e Terra, 1999. v. 1.

FILHO, Manoel Martins de Santana. Educação geográfica, docência e o contexto da pandemia covid19. Revista Tamoio, n. 1, 2020. Disponível em: https://www.epublicacoes.uerj.br/index.php/tamoios/article/view/50449/33467. Acesso em: 13 set. 2021.

GIDDENS, Anthony. O mundo na era da globalização. Lisboa: Presença, 2000.

GOMES, Marquiana de Freitas Vilas Boas et al. Ensino remoto emergencial no contexto da pandemia da covid - 19: trabalho e formação do professor de geografia no Paraná. Revista Pegada, vol. 21, n.3, 2020. Disponível em: https://revista.fct.unesp.br/index.php/pegada/article/download/7817/pdf. Acesso em: 13 set. 2021.

HODGES, Charles et al. Diferenças entre o aprendizado online e o ensino remoto de emergência. Revista da Escola, Professor, Educação e Tecnologia, v. 2, 2020. Disponível em: https://escribo.com/revista/index.php/escola/article/view/17/16. Acesso em: 17 ago. 2020.

IBGE. Cidades e Estados. Disponível em: https://www.ibge.gov.br/cidades-e-estados/ac.html. Acesso em: 22 ago. 2020.

LOPES, M. C. R.; MANCEBO, D. Trabalho Docente: compressão temporal, flexibilidade e prazer? Revista de Educação Pública, Cuiabá, v. 13, n. 24, p. 138-152, 2004.

MANFIO, Vanessa. O ensino de Geografia na pandemia covid-19: uma análise da perspectiva do lugar através de histórias em quadrinhos pelos alunos da escola municipal de ensino fundamental prof $^{a}$. Cândida Zasso de Nova Palma-RS. Disciplinarum Scientia (Ciências Humanas), v. 21, n. 2, $2020 . \quad$ Disponível em: https://periodicos.ufn.edu.br/index.php/disciplinarumCH/article/download/3424/2671. Acesso em: 13 set. 2021. 
MARI, Jair de Jesus. Quais os principais efeitos da pandemia na saúde mental?. Departamento De Comunicação Institucional da Universidade Federal de São Paulo. Disponível em: https://www.unifesp.br/reitoria/dci/noticias-anteriores-dci/item/4395-quais-os-principais-efeitos-dapandemia-na-saude-mental. Acesso em: 19 ago. 2020.

PRETTO, Nelson. O desafio de educar na era digital: educações. Revista Portuguesa de Educação, 2011, 24(1), pp. 95-118).

SINGLY, François de. Sociologia da família contemporânea. Rio de Janeiro: FGV, 2007. 208p. 